\title{
Production of (R)-3-hydroxybutyric acid by Arxula adeninivorans
}

\author{
Mateusz Biernacki ${ }^{1}$, Jan Riechen², Urs Hähnel ${ }^{1}$, Thomas Roick², Kim Baronian ${ }^{3}$ Rüdiger Bode ${ }^{4}$ \\ and Gotthard Kunze ${ }^{1^{*}}$
}

\begin{abstract}
(R)-3-hydroxybutyric acid can be used in industrial and health applications. The synthesis pathway comprises two enzymes, $\beta$-ketothiolase and acetoacetyl-CoA reductase which convert cytoplasmic acetyl-CoA to (R)-3-hydroxybutyric acid [(R)-3-HB] which is released into the culture medium. In the present study we used the non-conventional yeast, Arxula adeninivorans, for the synthesis enantiopure (R)-3-HB. To establish optimal production, we investigated three different endogenous yeast thiolases (Akat1p, Akat2p, Akat4p) and three bacterial thiolases (atoBp, thlp, phaAp) in combination with an enantiospecific reductase (phaBp) from Cupriavidus necator $\mathrm{H} 16$ and endogenous yeast reductases (Atpk2p, Afox2p). We found that Arxula is able to release (R)-3-HB used an existing secretion system negating the need to engineer membrane transport. Overexpression of thl and phaB genes in organisms cultured in a shaking flask resulted in $4.84 \mathrm{~g} \mathrm{~L}^{-1}(\mathrm{R})-3-\mathrm{HB}$, at a rate of $0.023 \mathrm{~g} \mathrm{~L}^{-1} \mathrm{~h}^{-1}$ over $214 \mathrm{~h}$. Fed-batch culturing with glucose as a carbon source did not improve the yield, but a similar level was reached with a shorter incubation period $\left[3.78 \mathrm{~g} \mathrm{~L}^{-1}\right.$ of (R)-3-HB at $89 \mathrm{~h}$ ] and the rate of production was doubled to $0.043 \mathrm{~g} \mathrm{~L}^{-1} \mathrm{~h}^{-1}$ which is higher than any levels in yeast reported to date. The secreted (R)-3-HB was $99.9 \%$ pure. This is the first evidence of enantiopure (R)-3-HB synthesis using yeast as a production host and glucose as a carbon source.
\end{abstract}

Keywords: (R)-3-HB, Arxula adeninivorans, $\beta$-Ketothiolase, Acetoacetyl-CoA reductase

\section{Introduction}

Production of chiral compounds is an area of interest not only for pharmaceuticals but also in the fine chemicals industry. Synthesis of these compounds can be carried out either chemically or biologically. The fact that stereoisomers can differ in physical, chemical and biological properties is important and because of this, racemic mixtures have to be separated before use in industrial products and drug synthesis. However biological synthesis can have an important advantage over chemical synthesis in that only one of the stereoisomers may be produced. Additionally, chemical synthesis requires expensive catalysts, toxic solvents and harsh conditions, whereas biological synthesis of stereoisomers occurs in an aqueous environment under mild conditions.

\footnotetext{
*Correspondence: kunzeg@ipk-gatersleben.de

1 Leibniz Institute of Plant Genetics and Crop Plant Research (IPK),

Correnstr. 3, 06466 Gatersleben, Saxony-Anhalt, Germany

Full list of author information is available at the end of the article
}

A number of microbiological syntheses have been developed to produce chiral compounds (Goldberg et al. 2007; Johanson et al. 2005). One of these is (R)-3-hydroxybutyric acid [(R)-3-HB], which is the monomer of the polymer polyhydroxybutyrate (PHB). (R)-3-HB has applications as a nutrition source and as a precursor for vitamins, antibiotics and pheromones (Sutter and Seebach 1983; Chen and Wu 2005; Tasaki et al. 1999). Recently (R)-3-HB has been investigated as a potential protective agent against neuronal death (Julio-Ampilas et al. 2015).

Microbiologically (R)-3-HB can be synthesized in two pathways. One of these includes synthesis of PHB followed by enzymatic depolymerisation to obtain (R)-3-HB. However, this method requires a two-step fermentation process, which is more expensive to operate (Shiraki et al. 2006). The second approach includes the direct synthesis of (R)-3-HB through condensation of two acetyl-CoA molecules to acetoacetyl-CoA by $\beta$-ketothiolase followed by reduction of the latter to 
3-hydroxybutyrate-CoA. Acetoacetyl-CoA reductase, the enzyme which catalyzes second conversion, is responsible for the stereoselectivity. The reductase, phaBp from Cupriavidus necator, produces the $(\mathrm{R})$ form while the reductase, hbdp from Clostridium acetobutylicum, synthesizes the (S) form (Tseng et al. 2009). The final steps involve removing the CoA group and secretion of the (R)-3-HB into the culture medium.

Processes described in the literature usually employ overexpression of two first enzymes and various systems for improving excretion step. Matsumoto et al. (2013) demonstrated production of (R)-3-HB from glucose at $5.2 \mathrm{~g} \mathrm{~L}^{-1}$ by overexpression of phaA and phaB genes from $C$. necator and pct, which encodes propionylCoA transferase from Clostridium propionicum, using Escherichia coli as a host organism. Employing another secretion system with tes $B$ gene (encoding E. coli thioesterase II), Liu et al. (2007) produced up to $12 \mathrm{~g} \mathrm{~L}^{-1}$ of (R)-3-HB. To date the maximal level of secreted (R)-3-HB achieved in a single fermentation process is $40.3 \mathrm{~g} \mathrm{~L}^{-1}$ using the bacteria Halomonas sp. KM-1 (Kawata et al. 2014). Recently, Saccharomyces cerevisiae has been reported as the first yeast to produce the second enantiomer form-(S)-3-HB. Yun et al. (2015) achieved $12 \mathrm{~g} \mathrm{~L}^{-1}$ of (S)-3-HB after a $220 \mathrm{~h}$ fed-batch fermentation using ethanol as the carbon source. However there are no reports describing the production of (R)-3-HB using yeast which use a simple carbon source such as glucose.

The non-conventional yeast Arxula adeninivorans, previously described as a valuable platform for production of recombinant proteins (Rauter et al. 2014; Chamas et al. 2015; Jankowska et al. 2013) and as a producer of the copolymer PHB-V (Terentiev et al. 2004), was proposed for the synthesis of (R)-3-HB. The advantages of using $A$. adeninivorans as a host are its wide substrate spectrum, its robustness and non-pathogenicity (Lindenkamp et al. 2012). Another advantage for using $A$. adeninivorans is that the wild type does not secrete (R)-3-HB but as demonstrated in this article, it has an endogenous secretion system that will export (R)-3-HB. There are cytosolic and mitochondrial thiolases in A. adeninivorans which could be used for (R)-3-HB production. Further there are two potentially useful reductases: Afox $2 p$ which is a peroxisomal multifunctional enzyme involved in fatty acid oxidation and known to catalyze the synthesis of the (R) form in S. cerevisiae (Hiltunen et al. 1992), and Atpk2p which is predicted to be mitochondrial 3-hydroxybutyryl dehydrogenase.

Here we describe the production of enantiopure (R)3 -HB by overexpression of genes encoding $\beta$-ketothiolase and acetoacetyl-CoA reductase in the yeast $A$. adeninivorans.

\section{Materials and methods}

Strains and cultivation condition

For cloning experiments and plasmid isolation, $E$. coli XL1 Blue [recA1 endA1 gyrA96 thi-1 hsdR17

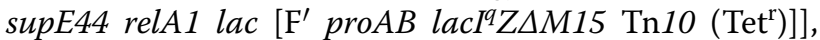
obtained from Invitrogen, was used. Growth media was Luria-Bertani (LB-Sigma, USA) supplemented with $100 \mathrm{mg} \mathrm{L}^{-1}$ ampicillin, $50 \mathrm{mg} \mathrm{L}^{-1}$ chloramphenicol or $50 \mathrm{mg} \mathrm{L}^{-1}$ kanamycin.

The wild-type strain $A$. adeninivorans LS3, originally isolated from wood hydrolysate in Siberia and deposited as A. adeninivorans SBUG 724 into the strain collection of the Department of Biology of the University of Greifswald (Kunze and Kunze 1994) was used as a control strain. The auxotrophic mutant, $A$. adeninivorans G1216 [aleu2 ALEU2::aade2] (Alvaro-Benito et al. 2012), was used as recipient strain. All strains were cultivated at $30{ }^{\circ} \mathrm{C}, 180 \mathrm{rpm}$ in $200 \mathrm{~mL}$ of broth in a 1-L flask. The medium was either selective yeast minimal medium supplemented with $50 \mathrm{~g} \mathrm{~L}^{-1}$ glucose and $43 \mathrm{mM} \mathrm{NaNO}$ (YMM-glc- $\mathrm{NO}_{3}$ ) (Tanaka et al. 1967; Rose et al. 1990) or non-selective yeast complex medium with the addition of $30 \mathrm{~g} \mathrm{~L}^{-1}$ glucose (YPD).

To investigate (R)-3-HB utilization, appropriate strains were first cultivated in YMM-glc- $\mathrm{NO}_{3}(2 \%$ glucose) and, after $36 \mathrm{~h}$ incubation at $30{ }^{\circ} \mathrm{C}$ cultures were centrifuged and cell pellets were washed with $\mathrm{YMM}-\mathrm{NO}_{3}$ (without glucose). Cells were then resuspended in $\mathrm{YMM}^{-\mathrm{NO}_{3}}$ media with $0,0.1$ and $0.2 \%(\mathrm{R})-3-\mathrm{HB}$ as a carbon source with starting $\mathrm{OD}_{600}=20$. The cultures were incubated at $30{ }^{\circ} \mathrm{C}$ for $48 \mathrm{~h}$ and (R)-3-HB and dry cell weight were measured at intervals over the incubation period.

Fed-batch cultures were performed in a 5-L fermenter (Sartorius, Germany) with conditions set to optimize growth and (R)-3-HB production. The temperature was maintained at $30{ }^{\circ} \mathrm{C}$ and a $\mathrm{pH}$ of 6.0 was controlled by the addition of $2.5 \mathrm{M} \mathrm{NaOH}$ or $1 \mathrm{M} \mathrm{H}_{2} \mathrm{SO}_{4}$. The level of oxygen was established at $\mathrm{pO}_{2}=1 \%$ (glucose feeding) or $\mathrm{pO}_{2}=40 \%$ (ethanol feeding) and maintained by the stirring rate. The culture was started in YPD followed by the addition of glucose and nitrogen to prevent the depletion of glucose and to maintain the metabolism of the organism. Foaming was reduced by the controlled addition of a silicone-based anti-foam agent (Strunktol SB 304, Schill + Seilacher GmbH, Germany).

\section{Plasmid construction}

The open reading frames (ORFs) of the bacterial genes were synthesized by GeneArt (Life Technologies) using optimized codon usage. ORFs originating from $A$. adeninivorans were obtained by PCR using genomic DNA of the wild type LS3 strain as a template and suitable primers (Table 1). One of the enzymes, Akat4p, was predicted 
(MITOPROT http://ihg.gsf.de/ihg/mitoprot.html) to be a mitochondrial protein. To obtain a cytoplasmic protein, ORFs without predicted leader sequence $\left(A K A T_{N 10}\right.$ and $A K A T_{N 17}$ version of basic $A K A T 4$ gene) were amplified as described above using additional primers. All complete ORFs were inserted into pBS-TEF1-PHO5-SA vector with pair of restriction sites to obtain expression modules containing the $A$. adeninivorans derived TEF1 strong constitutive promoter and the S. cerevisiae PHO5 terminator (Böer et al. 2009). A set of primers (Table 1) and the above plasmids were used in PCR to amplify the DNA fragments with an ORF, promoter, terminator and additional restriction sites. A two-step cloning procedure was used for the construction of the final expression plasmid based on Xplor2.4 system (Alvaro-Benito et al. 2012). The reductase gene (phaB [LT608132]) was used to make the TEF1-phaB-PHO5 fragment flanked

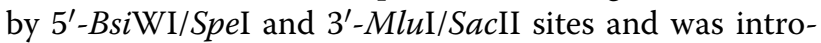
duced into the basic vector to create Xplor2.4-TEF1phaB-PHO5. Subsequently the expression module containing the TEF1 promoter, $\mathrm{PHO} 5$ terminator, different versions of $\beta$-ketothiolase gene (atoB [LT608129], thl [LT608130], phaA [LT609131], AKAT1 [LT608124], AKAT2 [LT609125], AKAT4 [LT608126], AKAT4 ${ }_{\text {N10 }}$

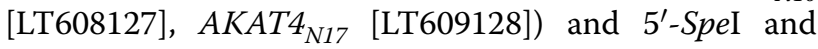
$3^{\prime}-B s i \mathrm{WI}$ restriction sites was cloned into the vector and final expression plasmids Xplor2.4-TEF1-thiolase-PHO5TEF1-phaB-PHO5 were generated. Additionally, for the genes of endogenous reductases (ATPK2 [LT632551],
AFOX2 [LT632550]) plasmids Xplor2.4-TEF1-thlPHO5-TEF1-ATPK2-PHO5 and Xplor2.4-TEF1-thlPHO5-TEF1-AFOX2-PHO5 were prepared in the same procedure.

All variants of the final plasmids were linearized with $A s c \mathrm{I}$ or $S b f l$ restriction enzymes and separately transformed into the auxotrophic strain, $A$. adeninivorans G1216 (Fig. 1).

\section{DNA manipulation and transformation}

Escherichia coli and A. adeninivorans cells were transformed as described previously (Böer et al. 2009). Stabilization of yeast transformants was performed with passaging on selective and non-selective media according to Klabunde et al. (2003). Isolation of plasmid DNA and DNA restrictions were carried out as described by Wartmann et al. (2003).

\section{Enzyme activity}

Both enzymatic activity assays were performed using permeabilized cells. Transformants were cultivated

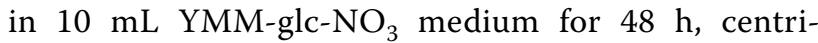
fuged and the cell pellet was resuspended in $100 \mathrm{mM}$ Tris- $\mathrm{HCl} \mathrm{pH} 8.1$ (or $50 \mathrm{mM}$ phosphate buffer $\mathrm{pH}$ $7.4+1 \mathrm{mM}$ DTT for the reductase assay) with $0.1 \%$ Triton X-100 and frozen at $-20{ }^{\circ} \mathrm{C}$. After thawing on ice, the cells were washed twice with buffer without Triton X-100 and the $\mathrm{OD}_{600}$ was adjusted to 1 before using in the assay.

Table 1 Oligonucleotide primers used for the construction of expression plasmids

\begin{tabular}{lll}
\hline Designation & Oligonucleotide sequence & Source \\
\hline ORFs primers & & Eurofins-Genomics \\
Akat1_start_Munl & TAGACAATTGATGGACAGACTCAACAACGTAGC \\
Akat1_stop_BamHI & GCAAGGATCCTTACTCCCGGATAAACAGAGC \\
Akat2_start_BamHI & TAGAGGATCCATGGAAAGAGCATCTAATCTTGCC \\
Akat2_stop_Notl & GCAAGCGGCCGCCTACTCCCTAATGAAGAGCG \\
Akat4_start_EcoRl & TAGAGAATTCATGTCTGTTTATATTCTTAGTGCTAAG \\
Akat4_N10_start_EcoRI & TAGAGAATTCATGACACCCATTGGTTCGTTTTTGGG \\
Akat4_N17_start_ECoRI & TAGAGAATTCATGGGATCTCTGTCTTCTCAGAC \\
Akat4_stop_BamHI & GCAAGGATCCTCAAACTCTCTCAATTACAAGAGC \\
Atpk2_start_BamHI & GCAAGGATCCATGCTACGACGGGGAATTC \\
Atpk2_stop_Notl & TAGCGGCCGCTCACAACTTTGCCCCAGC \\
Afox2_start_EcoRI & TAGAGAATTCATGTCGGTGCCAACGGC \\
Afox2_stop_Notl & TAGCGGCCGCTTAAAGCTTGGCTCCTCCG \\
Two-step cloning & \\
TEF1_Spel & TATAACTAGTTAGTAGCGCTAATCTATAATCAG \\
PHO5_BsiWl & CGGACGTACGAGCTTGCATGCCTGCAGA \\
TEF1_Spel_BsiWl & TATACTAGTACTTCGTACGCTCGACTTCAATCTATAATCAGTC \\
PHO5_Sacll_Mlul & GGATCCGCGGCCGAACGCGTAGCTTGCATGCCTGCAGATTTTAATC \\
\hline
\end{tabular}

Restriction sites were designated in italic 

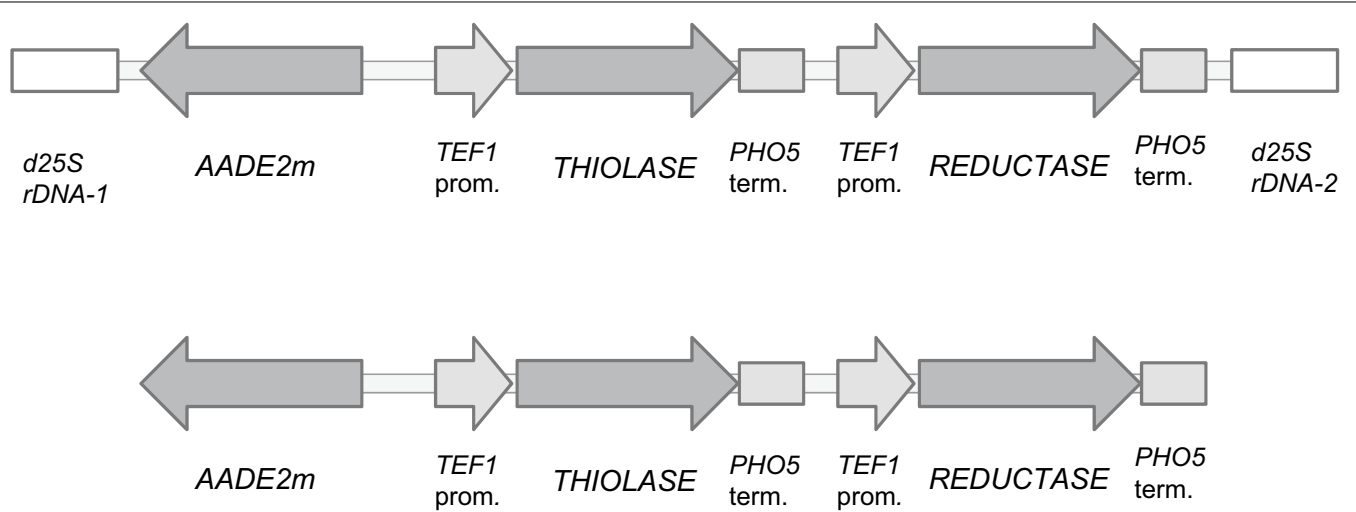

Fig. 1 Physical map of DNA transformed to auxotrophic A. adeninivorans G1216 strain for (R)-3-HB production. Fragments were obtained after linearization with AsCl (fragment included d25S rDNA sequences) or Sbfl (without d25S rDNA). THIOLASE is referred to atoB/thl/phaA/AKAT1/AKAT2/ AKAT4/AKAT4 $_{N 10} /$ AKAT4 $_{N 17}$ genes encoding different versions of $\beta$-ketothiolases and REDUCTASE gene to phaB/ATPK2/AFOX2 encoding acetoacetylCoA reductases. Both genes were fused with TEF1 promoter and PHO5 terminator to obtain two expression modules

\section{$\beta$-Ketothiolase}

Enzymatic activity was determined spectrophotometrically in the thiolysis direction using a modified version of the method described by Lindenkamp et al. (2012). The reaction mixture contained $100 \mathrm{mM}$ Tris $-\mathrm{HCl}(\mathrm{pH}$ 8.1), $25 \mathrm{mM} \mathrm{MgCl}_{2}, 100 \mu \mathrm{M}$ CoA and $40 \mu \mathrm{M}$ acetoacetylCoA; reaction was initiated with cells and carried out for $15 \mathrm{~min}$ at $30{ }^{\circ} \mathrm{C}$. After incubation, the reaction mixture was centrifuged at $3000 \times g$ for $1 \mathrm{~min}$ and the supernatant was analyzed spectrophotometrically (Infinite M200, TECAN). The decrease of the peak height was due to the disappearance of magnesium chelated acetoacetyl-CoA and was observed at $303 \mathrm{~nm}$. The concentration was calculated using the extinction coefficient of acetoacetylCoA $\left(16.5 \mathrm{mM}^{-1} \mathrm{~cm}^{-1}\right)$. Reactions without cells were incubated on ice and used as a blank.

One unit of $\beta$-ketothiolase activity was defined as the proportion of $1 \mathrm{nmol}$ acetoacetyl-CoA that was cleaved to acetyl-CoA in $1 \mathrm{~min}$ by $1 \mathrm{mg}$ of dry permeabilized cells.

\section{Acetoacetyl-CoA reductase}

A reductase activity assay was performed according to Kim et al. (2014) with slight modifications. The reaction mixture contained $50 \mathrm{mM}$ phosphate buffer $(\mathrm{pH}$ 7.4), $1 \mathrm{mM}$ DTT, $100 \mu \mathrm{M}$ acetoacetyl-CoA and $200 \mu \mathrm{M}$ $\mathrm{NADPH}$. After addition of permeabilized cells the reaction mixture was incubated for $30 \mathrm{~min}$ at $30{ }^{\circ} \mathrm{C}$, processed as above and oxidation of NADPH was monitored at $340 \mathrm{~nm}$. The extinction coefficient of NADPH was $6.22 \mathrm{mM}^{-1} \mathrm{~cm}^{-1}$. Blank samples were processed as for acetyltransferase. In the activity assay of Atpk $2 p$ and Afox2p, NADH was used as the cofactor. All other conditions were the same.
One unit of reductase activity was defined as the amount of $1 \mathrm{nmol} \mathrm{NADPH}$ oxidized to $\mathrm{NADP}^{+}$in $1 \mathrm{~min}$ by $1 \mathrm{mg}$ of dry permeabilized cells.

\section{Glucose assay}

To determine glucose usage by the cells, a modified DNS assay (based on dinitrosalicylic acid-Miller 1959), which can indicate reducing sugars in culture medium, was performed. $100 \mu \mathrm{L}$ DNS reagent (1\% 3,5-dinitrosalicylic acid, $0.4 \mathrm{M} \mathrm{NaOH}, 0.4 \mathrm{M} \mathrm{KOH}, 30 \%$ Rochelle salt) was added to $100 \mu \mathrm{L}$ of filtered and diluted culture supernatant, incubated in $95{ }^{\circ} \mathrm{C}$ for $10 \mathrm{~min}$, cooled to room temperature and the solution was analyzed at $530 \mathrm{~nm}$ with a reference wavelength of $600 \mathrm{~nm}$. The concentration of glucose was calculated from the measurement of standard dilutions.

\section{GC/MS analysis}

GC/MS analysis was used to determine the concentration of 3-HB in the supernatant. $0.1-1 \mathrm{~mL}$ culture supernatant was filtered through a $0.4 \mu \mathrm{m}$ syringe filter and lyophilized for $24 \mathrm{~h}$. The dry supernatants were subjected to propanolysis as described by Riis and Mai (1988) but with modification. $1.5 \mathrm{~mL} 1,2-\mathrm{DCE}$ and $1.5 \mathrm{~mL} n$-propanol- $\mathrm{HCl}$ solution $(4: 1 \mathrm{v} / \mathrm{v})$ was added to lyophilizate and incubated at $90{ }^{\circ} \mathrm{C}$ for $4 \mathrm{~h}$. After cooling to room temperature the reaction mixture was extracted twice with triple distilled $\mathrm{H}_{2} \mathrm{O}$ and the lower organic phase was taken for analysis in a Clarus ${ }^{\circledR} 680$ GC combined with Clarus $^{\circledR}$ SQ 8 S MS (PerkinElmer, USA) equipped with Elite-624 column (PerkinElmer, $30 \mathrm{~m} \times 0.5 \mathrm{~mm}, 1.4 \mu \mathrm{m}$ ). The GC program was set up as follows: initial $60{ }^{\circ} \mathrm{C}$ for $5 \mathrm{~min}$, ramping at $10{ }^{\circ} \mathrm{C} \mathrm{min} \mathrm{m}^{-1}$ to $200{ }^{\circ} \mathrm{C}$ and held for $2 \mathrm{~min}$ and then ramping at $5^{\circ} \mathrm{C} \min ^{-1}$ to $235^{\circ} \mathrm{C}$ and held for $10 \mathrm{~min}$. 
Commercial (R)-3-HB (Sigma-Aldrich) was used to construct a standard curve. The analysis was conducted in triplicate and results were analyzed by TurboMass 6.1 software.

\section{Enantiopurity analysis}

To check enantiopurity of 3-HB, a D-3-hydroxybutyric acid assay kit (Megazyme, Ireland), which is specific for (R)-3-HB, was used. Samples were prepared as recommended by the manufacturer and the results were compared with GC/MS measurements. Each sample was analyzed 5 times and the results meaned to give the final values.

\section{Statistics}

Two cultures were grown as independent experiments and measurements of enzymatic activity and GC/MS analysis were performed in triplicate. The final results are average values of the obtained data.

\section{Results}

\section{(R)-3-HB shaking flask screening}

Production of (R)-3-HB in A. adeninivorans was enabled by the overexpression of $\beta$-ketothiolase gene from different origins and acetoacetyl-CoA reductase gene from C. necator H16. Two endogenous reductase genes were functioning along with the thiolase gene from $C$. acetobutylicum (Table 2). The expression plasmids contained a YRC sequence (yeast rDNA integrative expression cassette) for homologous recombination or a YIC sequence

\section{Table 2 Overexpressed genes for (R)-3-HB production}

\begin{tabular}{|c|c|c|}
\hline Gene & $\begin{array}{l}\text { EMBL accession } \\
\text { number }\end{array}$ & Organism \\
\hline \multicolumn{3}{|c|}{$\beta$-Ketothiolase } \\
\hline phaA & LT608131 & C. necator H16 \\
\hline$a t o B$ & LT608129 & E. coli K12 \\
\hline thl & LT608130 & $\begin{array}{l}\text { C. acetobutylicum ATCC } \\
824\end{array}$ \\
\hline AKAT1 & LT608124 & A. adeninivorans LS3 \\
\hline AKAT2 & LT608125 & \\
\hline AKAT4 & LT608126 & \\
\hline AKAT4 $_{N 10}$ & LT608127 & \\
\hline AKAT4 $_{N 17}$ & LT608128 & \\
\hline \multicolumn{3}{|c|}{$\begin{array}{l}\text { Acetoacetyl-CoA } \\
\text { reductase }\end{array}$} \\
\hline phaB & LT608132 & C. necator $\mathrm{H} 16$ \\
\hline AFOX2 & LT632550 & A. adeninivorans LS3 \\
\hline ATPK2 & LT632551 & \\
\hline
\end{tabular}

N10/N17 subscript represent protein with sequence started with depicted amino acid from $\mathrm{N}$-terminal compare to wild type. All bacterial genes are codon optimized sequences. The constructed strains used in this article are the result of overexpression of one of the thiolase genes and one of the reductase genes (yeast integrative expression cassettes) for non-homologous recombination. The plasmids, Xplor2.4-atoB/thl/ phaA/AKAT1/AKAT2/AKAT4/AKAT4 ${ }_{\mathrm{N} 10} /$ AKAT4 $_{\mathrm{N} 17^{-}}$ phaB and Xplor2.4-thl-ATPK2/AFOX2 were constructed with each containing both production genes flanked with strong constitutive TEF1 promoter and PHO5 terminator. The endogenous auxotrophic $A A D E 2$ marker, which restores adenine synthesis pathway in $A$. adeninivorans, was used to select transformants. Plasmids were linearized with AscI (YRC) or SbfI (YIC) and transformed into the auxotrophic mutant, A. adeninivorans G1216, which is unable to grow on media that does not contain adenine (Fig. 1).

As well as the native endogenous thiolases, two versions of $A$. adeninivorans Akat4p, without a potential signaling peptide, were trialed. These variants were prepared by using another forward primer with an additional ATG start codon, processed and tested in parallel with the other thiolases.

The most productive strains in shake flask conditions were identified by incubating the transformants in YMM-glc- $\mathrm{NO}_{3}$ medium for $48 \mathrm{~h}$ and analyzing filtered supernatants by GC/MS. Except for G1216/YIC104AKAT4-phaB, G1216/YRC104-thl-ATPK2 and G1216/ YRC104-thl-AFOX2, all transgenic strains secreted (R)3-HB into the culture medium (Table 3). The highest level of product was found in the G1216/YIC104-phaAphaB clone $1\left(0.56 \mathrm{~g} \mathrm{~L}^{-1}\right)$. In contrast $(\mathrm{R})-3-\mathrm{HB}$ was not detected in negative control strain G1216/YIC104 (transformed with empty plasmid).

Table 3 (R)-3-HB production in shake flask using different media

\begin{tabular}{|c|c|c|c|c|}
\hline \multicolumn{3}{|c|}{ Overexpressed genes } & \multirow{2}{*}{\multicolumn{2}{|c|}{$\begin{array}{l}(\mathrm{R})-3-\mathrm{HB}\left[\mathrm{g} \mathrm{L}^{-1}\right] \\
\text { Shaking flask (maximal } \\
\text { level) }\end{array}$}} \\
\hline \multirow[t]{2}{*}{ Thiolase } & \multirow[t]{2}{*}{ Reductase } & \multirow[t]{2}{*}{$\begin{array}{l}\text { Shaking flask } \\
\text { (after } 48 \mathrm{~h} \text { ) }\end{array}$} & & \\
\hline & & & YMM & YPD \\
\hline$a t o B$ & \multirow[t]{8}{*}{ phaB } & $0.29 \pm 0.03$ & $0.88[140 \mathrm{~h}]$ & $2.74[214 \mathrm{~h}]$ \\
\hline thl & & $0.48 \pm 0.01$ & $2.15[152 \mathrm{~h}]$ & $4.87[214 \mathrm{~h}]$ \\
\hline phaA & & $0.56 \pm 0.05$ & $1.91[140 \mathrm{~h}]$ & 3.74 [214 h] \\
\hline AKAT1 & & $0.43 \pm 0.01$ & $0.34[120 \mathrm{~h}]$ & 2.76 [192 h] \\
\hline AKAT2 & & $0.38 \pm 0.03$ & $0.40[144 \mathrm{~h}]$ & $1.96[216 \mathrm{~h}]$ \\
\hline AKAT4 & & 0.00 & 0.00 & 0.00 \\
\hline AKAT4 $_{N 10}$ & & $0.46 \pm 0.05$ & $0.81[144 \mathrm{~h}]$ & $3.22[216 \mathrm{~h}]$ \\
\hline AKAT4 $_{N 17}$ & & $0.51 \pm 0.05$ & $0.53[120 \mathrm{~h}]$ & 2.38 [192 h] \\
\hline \multirow[t]{2}{*}{ thl } & AFOX2 & 0.00 & 0.00 & 0.00 \\
\hline & ATPK2 & 0.00 & 0.00 & 0.00 \\
\hline \multicolumn{2}{|c|}{ Negative control } & 0.00 & 0.00 & 0.00 \\
\hline
\end{tabular}

The final row is A. adeninivorans G1216/YIC104 negative control strain transformed an empty plasmid 


\section{Relationship between (R)-3-HB production and enzymes activities}

Production of (R)-3-HB depends on the activity of $\beta$-ketothiolase and acetoacetyl-CoA reductase as well as other factors, e.g. enzymes involved in removing the CoA moiety from (R)-3-HB-CoA and secretion into the culture medium. To check the relationship between acid production and enzymes activities several tests were done. The best transformants of each of the gene combinations were chosen. Permeabilization rather than disruption of cells was used to retain the optimal environment for the enzymes.

The activity of thiolase was assayed for thiolysis activity. The results showed a difference between bacterial and yeast enzymes (Fig. 2a) with enzyme activities of recombinant bacterial thiolases being similar (1.38 \pm 0.40 , $1.37 \pm 0.10$ and $1.29 \pm 0.05 \mathrm{U} \mathrm{mg}^{-1}$ for phaAp, atoBp and thlp, respectively), and while production of (R)-3-HB for G1216/YIC104-thl-phaB and G1216/YIC104-phaAphaB is comparable, the amount of (R)-3-HB secreted by G1216/YIC104-atob-phaB is significantly lower. This phenomenon suggests that enzyme activity is not the only factor responsible for (R)-3-HB production. Activities of $A$. adeninivorans thiolases are 2-4-times lower than those reported for the bacterial enzymes expressed in this yeast with values between $0.27 \pm 0.01$ and $0.65 \pm 0.15 \mathrm{U} \mathrm{mg}^{-1}$ for Akat4p and Akat2p respectively, which is associated with lower (R)-3-HB production in time course experiment (Fig. 3). The shorter versions of Akat4p without the predicted mitochondrial leader sequence (Akat $4 \mathrm{p}_{\mathrm{N} 10}$, Akat4 $\mathrm{p}_{\mathrm{N} 17}$ ) exhibited a higher enzymatic activity than native protein. Additionally G1216/YIC104-AKAT4phaB (with a native mitochondrial thiolase) does not produce (R)-3-HB. The negative control has a relatively low activity of $0.19 \pm 0.07 \mathrm{U} \mathrm{mg}^{-1}$ which corresponds to $13.5 \%$ of the maximal activity detected in the transformants.

The activity of acetoacetyl-CoA reductase, measured by the oxidation of NADPH, is similar for all transformants except for the negative control (transformed with an empty plasmid). The highest activity was exhibited by G1216/YIC104-AKAT4 ${ }_{\mathrm{N} 17}-$ phaB/1 with $2.41 \pm 0.08 \mathrm{U} \mathrm{mg}^{-1}$ while the lowest activity of $1.93 \pm 0.11 \mathrm{U} \mathrm{mg}^{-1}$ was seen in G1216/YIC104-AKAT1phaB/2. The negative control had $0.49 \pm 0.02 \mathrm{U} \mathrm{mg}^{-1}$ which corresponds to $20.4 \%$ of the highest detected activity. Enzyme activity was also seen in endogenous reductases Atpk2p and Afox2 using NADH as a cofactor instead of NADPH (Fig. 2c). The activity for G1216/ YRC104-thl-ATPK2 was higher with $1.31 \pm 0.07 \mathrm{U} \mathrm{mg}^{-1}$ compared to $0.64 \pm 0.07 \mathrm{U} \mathrm{mg}^{-1}$ for G1216/YRC104-thlAFOX2. Despite the enzymatic activity, both strains did not produce (R)-3-HB or (S)-3-HB. The negative control had $0.25 \pm 0.02 \mathrm{U} \mathrm{mg}^{-1}$ which corresponds to $18.4 \%$ of the highest detected activity. As an additional negative control NADPH-dependent phaB reductase was tested. The strain G1216/YIC104-thl-phaB also exhibited a little of activity with $0.40 \pm 0.02 \mathrm{U} \mathrm{mg}^{-1}$.

\section{Time course experiment}

Changes of (R)-3-HB concentration in culture media were checked in shake flask time course experiments. The best strains of each gene combination were cultivated in YMM-glc- $\mathrm{NO}_{3}$ and $\mathrm{YPD}+30 \mathrm{~g} \mathrm{~L}^{-1}$ glucose (to compensate sugar content). Each day samples were taken and (R)-3-HB and glucose concentration were measured; growth rate was determined by lyophilization of the cell pellet and determining the dry cell weight $(\mathrm{dcw})$. In both media, the highest level of (R)-3-HB was observed with G1216/YIC104-thl-phaB clone 4 (Fig. 3). There was no production of (R)-3-HB in G1216/YIC104-AKAT4-phaB, G1216/YRC104-thl-ATPK2 and G1216/YRC104-thlAFOX2 strains. In a rich medium, the concentration of the product rose to $4.87 \mathrm{~g} \mathrm{~L}^{-1}$ at $214 \mathrm{~h}$ with a productivity of $22.8 \mathrm{mg} \mathrm{L}^{-1} \mathrm{~h}^{-1}$. The decrease of (R)-3-HB level after this point is possibly caused by consumption of (R)3 -HB by $A$. adeninivorans as a carbon source. The results with the minimal medium were proportionally the same but the lower nutrient level resulted in a shorter incubation period and a lower productivity (maximum (R)3 -HB level at $152 \mathrm{~h}$ was $2.15 \mathrm{~g} \mathrm{~L}^{-1}$ and the productivity was $14.1 \mathrm{mg} \mathrm{L}^{-1} \mathrm{~h}^{-1}$ ). The secretion of (R)-3-HB started rapidly at the end of the exponential growth phase which means the production is biomass dependent rather than growth dependent i.e. production in idiophase when the carbon source has been depleted. This suggests that, as in other yeast, glucose is not directly converted to cytosolic acetyl-CoA, which is a necessary precursor for (R)-3-HB production (De Jong-Gubbels et al. 1995; Chen et al. 2012).

The enzymatic activities during extended cultivations were measured for the strains with the middle to highest (R)-3-HB production rates (Fig. 2b). The reductase in G1216/YIC104-thl-phaB reached $2.50 \pm 0.10 \mathrm{U} \mathrm{mg}^{-1}$ after $48 \mathrm{~h}$ with constant activity until the end of cultivation. A similar situation was observed for G1216/ YIC104-atob-phaB but with a lower maximal activity of $2.28 \pm 0.09 \mathrm{U} \mathrm{mg}^{-1}$ after $240 \mathrm{~h}$. Measurement of thiolase activity for G1216/YIC104-thl-phaB shows an incremental increase in its activity to $2.75 \pm 0.21 \mathrm{U} \mathrm{mg}^{-1}$ at the end of incubation, with an increased rate between $48 \mathrm{~h}$ and $192 \mathrm{~h}$. G1216/YIC104-atoB-phaB showed a steep rise in enzymatic activity starting at $144 \mathrm{~h}$ and reaching $2.16 \pm 0.06 \mathrm{U} \mathrm{mg}^{-1}$ at the end of the cultivation at $288 \mathrm{~h}$. These results can only partially explain the difference between (R)-3-HB productions by both 


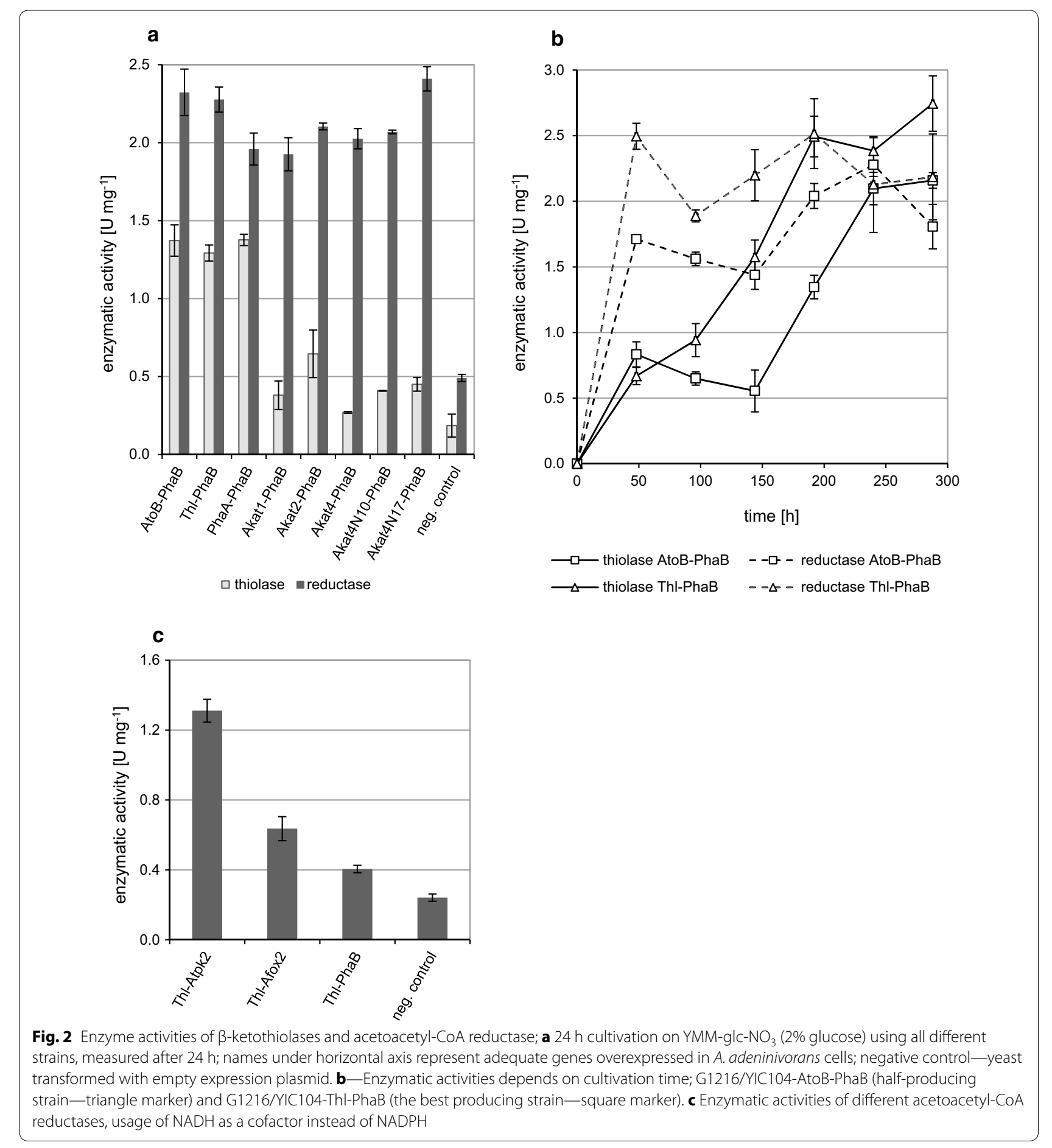

strains. The threefold higher enzymatic activity of thiolase in contrast to only 1.75-fold higher (R)-3-HB production by G1216/YIC104-thl-phaB and G1216/ YIC104-atoB-phaB shows that it is not only enzymatic activity that influences (R)-3-HB synthesis and secretion.

\section{(R)-3-HB utilization}

One of the problems with (R)-3-HB synthesis by $A$. adeninivorans is degradation of this acid at the end of the synthesis stage. To check the influence of overexpressed genes on this phenomenon, an additional strain with an overexpressed phaB gene was constructed. 


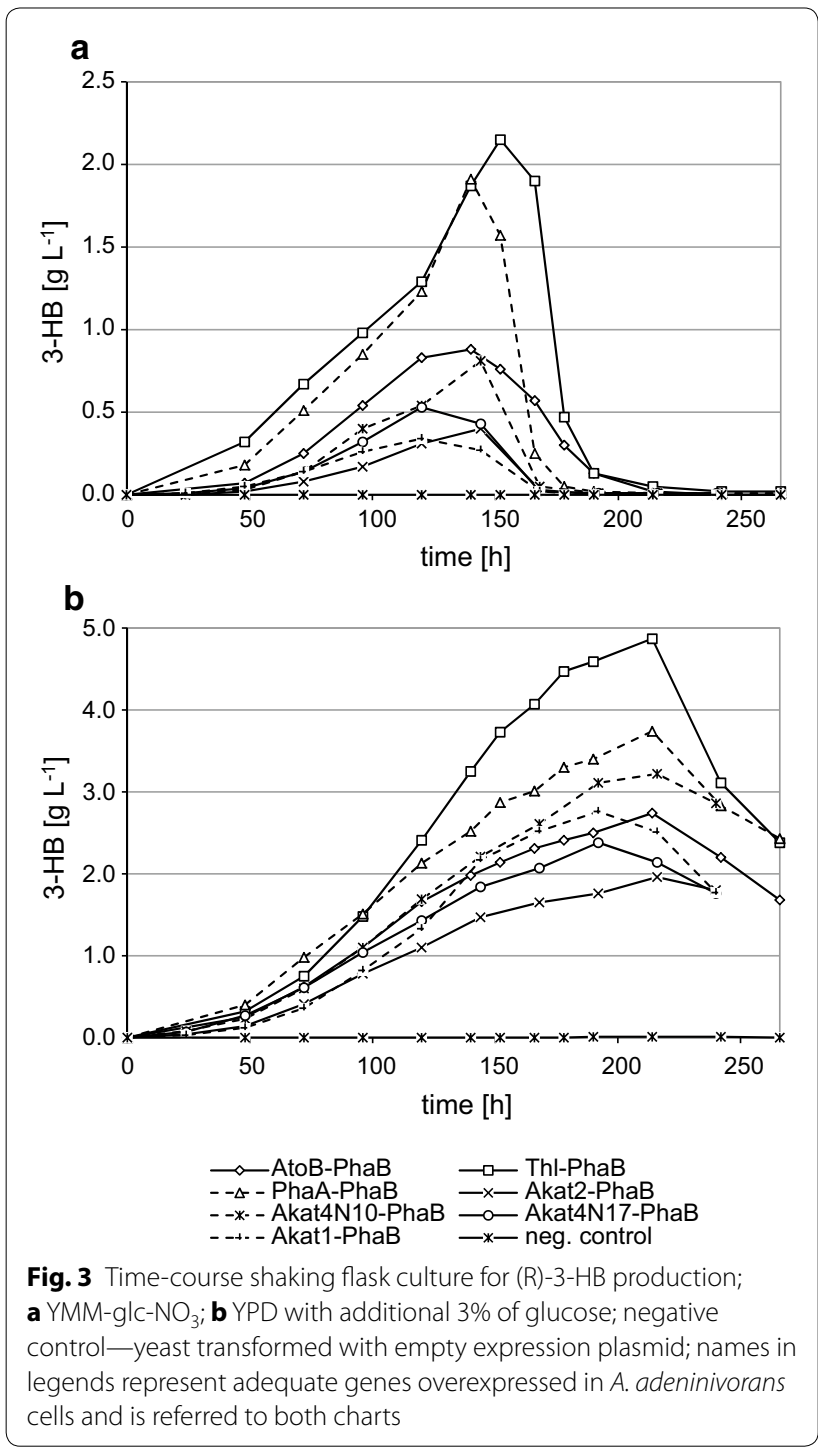

G1216/YIC104-phaB, G1216/YIC104-thl-phaB and G1216/YIC104 (negative control) were used in time course experiment. After the medium shift, cultures were fed with different concentration of (R)-3-HB and cultivated for $48 \mathrm{~h}$.

The results of (R)-3-HB concentration and cell mass $(\mathrm{dcw})$ revealed that the overexpression of the $p h a B$ gene alone has no influence on (R)-3-HB utilization compared to the negative control (Fig. 4a). In G1216/YIC104-thlphaB we observed a slightly lower rate of consumption but this is possibly due to ability of this strain to a parallel production of (R)-3-HB. Additionally, the decrease of cell mass during cultivation showed that carbon from (R)$3-\mathrm{HB}$ is directed to secondary metabolism rather than to growth (Fig. 4b).

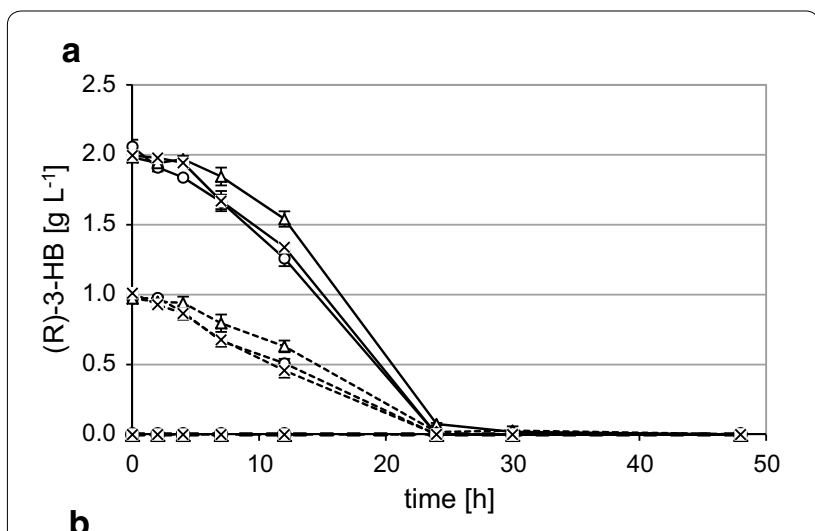

b

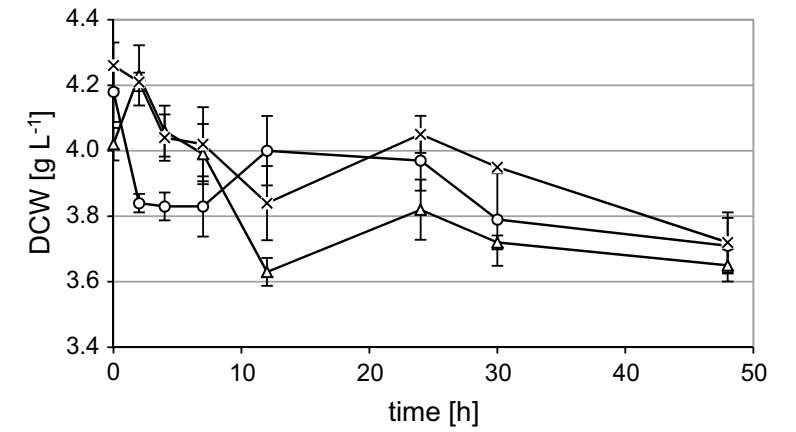

Fig. 4 (R)-3-HB utilization. After the medium shift, cultures were fed with different (R)-3-HB concentrations. Straight, dashed and dot-dashed lines correspond to the initial $0.2,0.1$ and $0 \%$ of (R)-3-HB respectively. Triangles, crosses and circles correspond to strains G1216/ YIC104-thl-phaB, G1216/YIC104-phaB and G1216/YIC104 (negative control) respectively. Cell masses were shown only for the $0.2 \%$ (R)3-HB concentration because similar growth behavior was observed for the all strains. $\mathbf{a}(\mathrm{R})-3-\mathrm{HB}$ concentration, $\mathbf{b}$ cell mass (dcw)

\section{Fermentation results}

Time course analysis indicated that (R)-3-HB can be used by $A$. adeninivorans as a carbon source. To increase production levels and to prevent product consumption, nutrients were provided in fed-batch mode. Based on the results from the shake flask experiments, A. adeninivorans G1216/YIC104-thl-phaB and a modified yeast complex media were selected for the optimization of (R)3-HB production.

The first fermentations showed that in aerobic conditions $\left(40 \% \mathrm{pO}_{2}\right),(\mathrm{R})-3-\mathrm{HB}$ is consumed rapidly after glucose depletion, reaching maximum of $1.3 \mathrm{~g} \mathrm{~L}^{-1}$ of product after $26 \mathrm{~h}$ (data not shown) and production doesn't occur again despite of glucose feeding. To try to counter the degradation of (R)-3-HB, hypoxic conditions $\left(1 \% \mathrm{pO}_{2}\right)$ were used and the culture was fed with glucose and nitrogen, beginning before the depletion of the initial glucose. As expected, a longer growth lag phase occurred, $21 \mathrm{~h}$ compared to $5 \mathrm{~h}$ 
for growth in optimal conditions (data not shown). The end of the logarithmic phase occurred at $42 \mathrm{~h}$ with a specific growth rate of $0.066 \mathrm{~h}^{-1}$. Production of (R)-3-HB started from the beginning of log phase and rose steadily up to $76 \mathrm{~h}$, which was when the initial glucose became depleted. From this point, the concentration increased from $1.66 \mathrm{~g} \mathrm{~L}^{-1}$ at $76 \mathrm{~h}$ to $3.76 \mathrm{~g} \mathrm{~L}^{-1}$ after $89 \mathrm{~h}$ of cultivation and attaining a productivity of $0.043 \mathrm{~g} \mathrm{~L}^{-1} \mathrm{~h}^{-1}$ (Fig. 5a). Longer cultivation however, caused (R)-3-HB degradation as was seen in shake flask experiments. The increase in (R)3 -HB production between 76 and $89 \mathrm{~h}$ was correlated with the use of ethanol by Arxula and once the ethanol was depleted, (R)-3-HB was then used as the carbon source.
To check if Arxula is able to produce (R)-3-HB from ethanol only, fed-batch fermentations were performed (Fig. 5b). The best conditions for ethanol feeding were establish by carrying out fermentation in aerobic conditions $\left(\mathrm{pO}_{2}=40 \%\right)$. A higher oxygen level resulted in faster growth with the end of logarithmic phase occurring at $25 \mathrm{~h}$. The production of (R)-3-HB started around $15 \mathrm{~h}$ at $0.13 \mathrm{~g} \mathrm{~L}^{-1}$ and increased to $3.28 \mathrm{~g} \mathrm{~L}^{-1}$ at $70 \mathrm{~h}$ with productivity of $0.047 \mathrm{~g} \mathrm{~L}^{-1} \mathrm{~h}^{-1}$. Despite the continuous ethanol feeding the level of (R)-3-HB remained constant. After feeding was complete, (R)-3-HB, as in other fermentations, was immediately degraded by Arxula. Additionally, despite the aerobic conditions, the amount of cell mass at the end of cultivation was lower than for hypoxic conditions and glucose feeding ( $35.2 \mathrm{~g} \mathrm{~L}^{-1}$ compare to $53.1 \mathrm{~g} \mathrm{~L}^{-1}$ ).
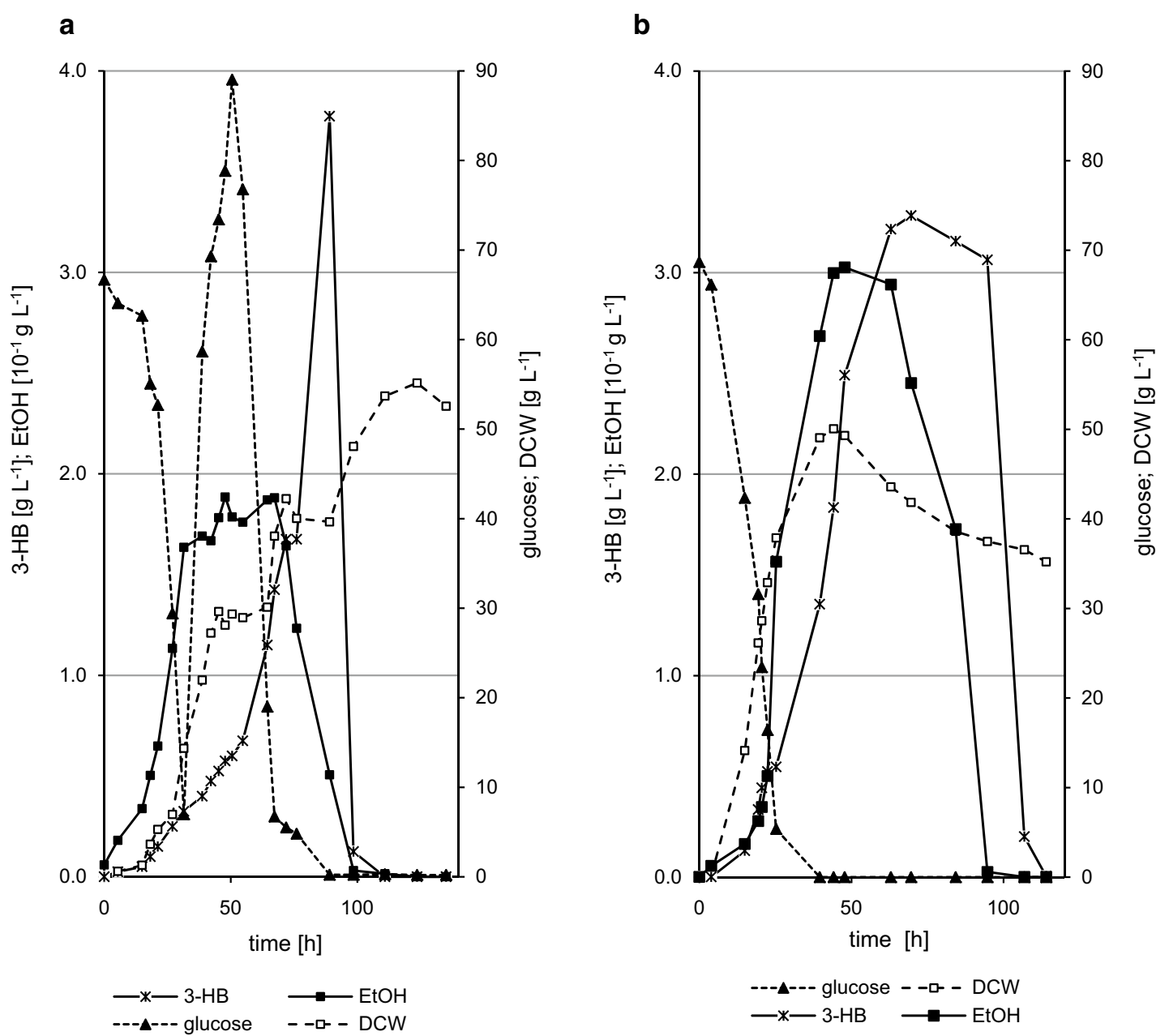

Fig. 5 Production of (R)-3-HB by fed-batch cultivation of A. adeninivorans G1216/YIC104-ThI-PhaB: a under hypoxic condition ( $\left.\mathrm{pO}_{2}=1 \%\right)$ with glucose feeding; b under aerobic condition $\left(\mathrm{pO}_{2}=40 \%\right)$ with ethanol feeding. Feeding phase was started before initial glucose was completely consumed. During experiment the concentration of (R)-3-HB, glucose, ethanol and cell mass were measured 


\section{Enantiopurity}

Because of the specificity of acetoacetyl-CoA reductase, the final product was predicted to be the (R)-enantiomer (Tseng et al. 2009). GC/MS measurement using the standard column is not able to distinguish between (R) and (S) forms and thus to check enantiopurity of (R)3 - HB the results from GC/MS measurement and those from D-3-hydroxybutyric acid assay kit were compared. The sample was taken after $120 \mathrm{~h}$ cultivation of G1216/ YIC104-thl-phaB in rich medium and concentration of (R)-3-HB was measured by both methods. The concentration of (R)-3-HB quantified by GC/MS and the kit assay was same $\left(3.029 \pm 0.044\right.$ and $3.027 \pm 0.090 \mathrm{~g} \mathrm{~L}^{-1}$ respectivly). Because the kit assay can recognize only (R)3 -HB and there is no difference between both results, it confirms that (R)-3-HB produced by $A$. adeninivorans is a pure enantiomer. Additionally the (S)-3-HB negative control showed no response using the same assay kit.

\section{Discussion}

Overexpression of $\beta$-ketothiolase and acetoacetyl-CoA reductase genes makes the yeast $A$. adeninivorans able to produce 3-hydroxybutyric acid. Additionally, the lack or low level of expression of endogenous enzymes able to produce (R)-3-HB and the overexpression of an enantiospecific reductase led to the secretion of enantiomerically pure (R)-3-HB.

Initial investigations, which included overexpression of different versions of thiolase genes from bacteria and $A$. adeninivorans and one reductase gene from C. necator $\mathrm{H} 16$ resulted in the production of (R)-3-HB by strains with all gene combinations, except G1216/ YIC104-AKAT4-phaB which had a mitochondrial thiolase. The highest concentration was achieved with G1216/YIC104-thl-phaB. Additionally, strains with overexpressed $t h l$ gene and two endogenous reductase genes did not secrete 3-HB. Analysis of two different media for (R)-3-HB production in time course shake flask experiments revealed greater synthesis by all strains grown in a yeast complex medium (YPD) compared to growth in a minimal medium with nitrate $\left(\mathrm{HMM}\right.$-glc- $\left.\mathrm{NO}_{3}\right)$. Additionally, the degradation of (R)-3-HB occurred faster in the $\mathrm{HMM}$-glc- $\mathrm{NO}_{3}$ medium. Those differences could be caused by more secondary metabolites for metabolism after the depletion of the initial glucose in YPD medium.

Comparison of expressed thiolases from different origins shows that the enzyme activity of the bacterial enzymes is at least twice as high than for $A$. adeninivorans enzymes and that enzymatic activity is not directly related to (R)-3-HB production. While G1216/ YIC104-thl-phaB with bacterial thiolase exhibits the highest production and relatively high enzymatic activity, the G1216/YIC104-atoB-phaB strain that has a different bacterial thiolase, shows the highest activity, however it has a (R)-3-HB production level lower than that for G1216/YIC104-AKAT4 ${ }_{\mathrm{N} 10}$-phaB containing an overexpressed $A$. adeninivorans gene. Those disparities have to be explained by other factors, for example, specificity of thiolases, its kinetic constants, optimal $\mathrm{pH}$ and temperature. Comparison of reductase enzymatic activity shows that bacterial phaBp has an almost twice the activity than endogenous Atpk2p and four times the activity of Afox2p. While strains with overexpressed thiolase and phaB genes are able to produce (R)-3-HB, the strains with $A T P K 2$ or AFOX2 genes did not secrete either the (R) form or (S) form of 3-HB. This effect can be caused by compartmentalization of protein to different organelles. Bacterial phaBp is placed in cytosol, while Atpk2p and Afox $2 p$ are expressed in the mitochondria and peroxisome respectively. It is likely that inefficient transport of intermediates between cell organelles could impede (R)3-HB production.

Two of the A. adeninivorans LS3 thiolases without potential mitochondrial signaling sequence were amplified and tested. Comparison of Akat $4 \mathrm{p}_{\mathrm{N} 10}$ and Akat$4 \mathrm{p}_{\mathrm{N} 17} \mathrm{p}$ with wild type Akat $4 \mathrm{p}$ reveals interesting results. Enzymatic activities of shorter versions are slightly higher than for the wild type. Production of (R)-3-HB is relatively high for G1216/YIC104-AKAT4 ${ }_{\mathrm{N} 10}-\mathrm{phaB}$ and G1216/YIC104-AKAT4 ${ }_{\mathrm{N} 17}-\mathrm{phaB}$, especially for the former, while the strain G1216/YIC104-AKAT4-phaB does not exhibit any secretion of the product. These results show that cytosolic targeting of protein is necessary for (R)-3-HB production. Additionally, enzymes with deleted signaling sequence retained their enzymatic activity, and were able to synthesis of (R)-3-HB. This strategy could be employed in other applications such as express mitochondrial or peroxysomal enzymes in cytoplasm. Further analysis of shake flask cultures showed an increase in secretion with longer cultivation periods (up to $214 \mathrm{~h}$ ). Increased late production can be hypothetically explained by two factors. Firstly, a flux of acetyl-CoA at the beginning of cultivation on glucose is used in the mitochondria for energy production (Krivoruchko et al. 2015) and due to oleaginous nature of Arxula, used for fatty acid synthesis (Ratledge 2002). After glucose depletion fatty acids can be reduced and more acetyl-CoA shifted to (R)-3-HB synthesis pathway. Additionally the correlation between ethanol and (R)-3-HB levels revealed that acetyl-CoA coming from ethanol utilization is responsible for high secretion peak and it seems to be the main source of (R)-3-HB precursor. This effect can be explained by fact that acetyl-CoA from ethanol is localized in cytoplasm (De Jong-Gubbels et al. 1995) and can be directly converted by $\beta$-ketothiolase. Secondly, the enzymes responsible for secretion of (R)-3-HB in A. adeninivorans LS3 
are currently unknown and therefore cannot be influenced. Late (R)-3-HB production could also indicate that this excretion system is inefficient. Additionally, it is unknown whether secretion mechanism is active or nonactive. There are more than 10 genes in A. adeninivorans LS3 which could express proteins involved in this system, but most of them are located in mitochondria or peroxisomes. Nevertheless, there exist at least three transferases which are localized in cytoplasm. Two of them are constitutively expressed and one is induced by oleic acid. Additionally, these enzymes exhibit high activity for the transfer of the CoA moiety to succinyl-CoA (data not published). Liu et al. (2007) obtained up to $12 \mathrm{~g} \mathrm{~L}^{-1}$ of (R)-3-HB in E. coli using another system with thioesterase II (tesB) for removing CoA from (R)-3-HB-CoA, thus facilitating secretion of the acid into the medium. A similar protein occurs in A. adeninivorans LS3 and is analogous to Pte1 from S. cerevisiae (Maeda et al. 2006) but both are targeted to peroxisomes. To improve production of (R)-3-HB in A. adeninivorans by genetic modification, an endogenous secretion system could be overexpressed or an exogenous secretion system could be expressed.

Utilization of (R)-3-HB as a carbon source cannot be explained by as an effect of overexpressed genes. The negative control strain and strain with overexpressed acetoacetyl-CoA reductase gene have a similar (R)-3-HB utilization behavior and (R)-3-HB producing strain G1216/ YIC-104-thl-phaB catabolizes acid slightly slower but this effect can be explained by parallel production of $(\mathrm{R})$ 3-HB. These results confirmed that (R)-3-HB can be used by $A$. adeninivorans as a carbon source and that this process currently cannot be controlled.

To boost the production of (R)-3-HB the controllable conditions of fed-batch cultivation was employed. Optimization of fermentation conditions using different aeration rates revealed that (R)-3-HB secretion is highly dependent on oxygen level. Fully aerobic conditions lead to rather fast (R)-3-HB production but also rapid product consumption. Three-fold higher synthesis level occurs for hypoxic conditions $\left(\mathrm{pO}_{2}=1 \%\right)$ but a longer incubation period was required ( $89 \mathrm{~h}$ compare to $26 \mathrm{~h}$ ). However under these conditions degradation of acid also occurred. In both cases after depletion of basic carbon sources, endogenous ethanol is consumed and causes an increase in production, however after ethanol is completely catabolized, (R)-3-HB is rapidly consumed by Arxula and it becomes difficult to maintain a high production level. Using ethanol as the main carbon source did not improve the secretion level, which could mean there is a maximal level of (R)-3-HB in fed-batch fermentation. Despite using controlled hypoxic conditions and higher glucose or ethanol concentrations, the level of (R)-3-HB never exceeded the concentration obtained in shake flask cultures. Here we have demonstrated that the nonconventional yeast $A$. adeninivorans is able to produce enantiomerically pure (R)-3-HB up to $4.87 \mathrm{~g} \mathrm{~L}^{-1}$ in shaking flasks and $3.76 \mathrm{~g} \mathrm{~L}^{-1}$ in fed-batch culture. In future work, we will attempt to increase the secretion level and decrease the cultivation period. Genetic engineering an alternative membrane transport system and the use of different carbon sources appear to be promising strategies for this enhancement.

\section{Abbreviations \\ (R)-3-HB: (R)-3-hydroxybutyric acid; PHB: polyhydroxybutyrate; PHB-V: poly(hydroxybutyrate-co-hydroxyvalerate); CoA: coenzyme A; GC/MS: gas chromatography/mass spectrometry; DCE: 1,2-dichloroethane; YRC: yeast rDNA integrative expression cassette; YIC: yeast integrative expression cas- sette; dcw: dry cell weight.}

\section{Authors' contributions}

MB carried out the molecular genetic studies, microorganisms' cultivation, enzymatic activity assays and drafted the manuscript. JR carried out the GC/ MS analysis. UH searched for appropriate genes and carried out the molecular genetic studies. TR participated in the design of the study. KB provided writing assistance and helped in results analyzing. RB participated in the design of the study and provided excellent biochemical knowledge support. GK conceived of the study and participated in its design and coordination and helped to draft the manuscript. All authors read and approved the final manuscript.

\section{Author details}

${ }^{1}$ Leibniz Institute of Plant Genetics and Crop Plant Research (IPK), Correnstr. 3, 06466 Gatersleben, Saxony-Anhalt, Germany. ${ }^{2}$ Jäckering Mühlen- und Nährmittelwerke GmbH, Vorsterhauser Weg 46, 59007 Hamm, Germany. ${ }^{3}$ School of Biological Sciences, University of Canterbury, Private Bag 4800, Christchurch, New Zealand. ${ }^{4}$ Institute of Microbiology, University of Greifswald, Jahnstr. 15, 17487 Greifswald, Germany.

\section{Acknowledgements}

The researchers thank Sylvane Stegmann and Felix Bischoff for their support.

\section{Competing interests}

The authors declare that they have no competing interests.

\section{Ethical approval and consent to participate}

This article does not contain any studies with human participants or animals performed by any of the authors.

\section{Funding}

The research work was supported by Grant from the German Federal Ministry for Economic Affairs and Energy (BMWi-Grant No. KF2131625SB3).

Received: 5 December 2016 Accepted: 11 December 2016

Published online: 03 January 2017

\footnotetext{
References

Alvaro-Benito M, Fernández-Lobato M, Baronian K, Kunze G (2012) Assessment of Schwanniomyces occidentalis as a host for protein production using the wide-range Xplor2 expression platform. Appl Microbiol Biotechnol 97:4443-4456. doi:10.1007/s00253-012-4527-9

Böer E, Bode R, Mock HP, Piontek M, Kunze G (2009) Atan1 p-an extracellular tannase from the dimorphic yeast Arxula adeninivorans: molecular cloning of the ATAN1 gene and characterization of the recombinant enzyme. Yeast 26:323-337. doi:10.1002/yea.1669

Chamas A, Giersberg M, Friedrich K, Sonntag F, Kunze D, Uhlig S, Simon K, Baronian K, Kunze G (2015) Purification and immunodetection of the
} 
complete recombinant HER-2[neu] receptor produced in yeast. Protein Expr Purif 105:61-70. doi:10.1016/j.pep.2014.10.004

Chen GQ, Wu Q (2005) Microbial production and applications of chiral hydroxyalkanoates. Appl Microbiol Biotechnol 67:592-599. doi:10.1007/ s00253-005-1917-2

Chen Y, Siewers V, Nielsen J (2012) Profiling of cytosolic and peroxisomal acetyl-CoA metabolism in Saccharomyces cerevisiae. PLoS ONE 7:e42475. doi:10.1371/journal.pone.0042475

De Jong-Gubbels P, Vanrolleghem P, Heijnen S, van Dijken JP, Pronk JT (1995) Regulation of carbon metabolism in chemostat cultures of Saccharomyces cerevisiae grown on mixtures of glucose and ethanol. Yeast 11:407-418. doi:10.1002/yea.320110503

Goldberg K, Schroer K, Lütz S (2007) Biocatalytic ketone reduction-a powerful tool for the production of chiral alcohols - part II: wholecell reductions. Appl Microbiol Biotechnol 76:249-255. doi:10.1007/ s00253-007-1005-X

Hiltunen JK, Wenzel B, Beyer A, Erdmann R, Fossa A, Kunau WH (1992) Peroxisomal multifunctional beta-oxidation protein of Saccharomyces cerevisiae. Molecular analysis of the fox 2 gene and gene product. J Biol Chem 267(10):6646-6653

Jankowska DA, Faulwasser K, Schult-Trautwein A, Cordes A, Hoferichter P, Klein C, Bode R, Baronian K, Kunze G (2013) Arxula adeninivorans recombinant adenine deaminase and its application in the production of food with low purine content. J Appl Microbiol 115:1134-1146. doi:10.1111/ jam. 12317

Johanson T, Michael K, Gorwa-Grauslund MF (2005) Strain engineering for stereoselective bioreduction of dicarbonyl compounds by yeast reductases. FEMS Yeast Res 5:513-525. doi:10.1016/j.femsyr.2004.12.006

Julio-Ampilas A, Montiel T, Soto-Tinoco E, Geronimo-Olvera C, Massieu $L$ (2015) Protection of hypoglycemia-induced neuronal death by $\beta$-hydroxybutyrate involves the preservation of energy levels and decreased production of reactive oxygen species. J Cereb Blood Flow Metab 35:851-860. doi:10.1038/jcbfm.2015.1

Kawata Y, Ando H, Matsushita I, Tsubota J (2014) Efficient secretion of (R)3-hydroxybutyric acid from Halomonas sp. KM-1 by nitrate fed-batch cultivation with glucose under microaerobic conditions. Bioresour Technol 156:400-403. doi:10.1016/j.biortech.2014.01.073

Kim J, Chang JH, Kim EJ, Kim KJ (2014) Crystal structure of (R)-3-hydroxybutyryl-CoA dehydrogenase PhaB from Ralstonia eutropha. Biochem Biophys Res Commun 443:783-7883. doi:10.1016/j.bbrc.2013.10.150

Klabunde J, Kunze G, Gellissen G, Hollenberg CP (2003) Integration of heterologous genes in several yeast species using vectors containing a Hansenula polymorpha-derived rDNA-targeting element. FEMS Yeast Res 4:185-193. doi:10.1016/S1567-1356(03)00148-X

Krivoruchko A, Zhang Y, Siewers V, Chen Y, Nielsen J (2015) Microbial acetylCoA metabolism and metabolic engineering. Metab Eng 28:28-42. doi:10.1016/j.ymben.2014.11.009

Kunze G, Kunze I (1994) Characterization of Arxula adeninivorans strains from different habitats. Antonie Van Leeuwenhoek 65:29-34. doi:10.1007/ BF00878276

Lindenkamp N, Volodina E, Steinbüchel A (2012) Genetically modified strains of Ralstonia eutropha $\mathrm{H} 16$ with $\beta$-ketothiolase gene deletions for production of copolyesters with defined 3-hydroxyvaleric acid contents. Appl Environ Microbiol 78:5375-5383. doi:10.1128/AEM.00824-12

Liu Q, Ouyang SP, Chung A (2007) Microbial production of R-3-hydroxybutyric acid by recombinant E. coli harboring genes of phbA, phbB, and tesB. Appl Microbiol Biotechnol 76:811-818. doi:10.1007/s00253-007-1063-0

Maeda I, Delessert S, Hasegawa S, Seto Y, Zuber S, Poirer Y (2006) The peroxisomal acyl-CoA thioesterase pte $1 \mathrm{p}$ from Saccharomyces cerevisiae is required for efficient degradation of short straight chain and branched chain fatty acids. J Biol Chem 281:11729-11735. doi:10.1074/jbc. M511762200

Matsumoto K, Okei T, Honma I, Ooi T, Aoki H, Taguchi S (2013) Efficient (R)3-hydroxybutyrate production using acetyl CoA-regenerating pathway catalyzed by coenzyme A transferase. Appl Microbial Biotechnol 97:205-210. doi:10.1007/s00253-012-4104-2

Miller GL (1959) Use of dinitrosalicylic acids reagent for determination of reducing sugar. Anal Chem 31:426

Ratledge C (2002) Regulation of lipid accumulation in oleaginous microorganisms. Biochem Soc Trans 30:1047-1050. doi:10.1042/bst0301047
Rauter M, Kasprzak J, Becker K, Baronian K, Bode R, Kunze G, Vorbrodt HM (2014) ADH from Rhodococcus ruber expressed in Arxula adeninivorans for the synthesis of 1-(S)-phenylethanol. J Mol Catal B: Enzym 104:8-16. doi:10.1016/j.molcatb.2014.02.015

Riis V, Mai W (1988) Gas chromatographic determination of poly$\beta$-hydroxybutyric acid in microbial biomass after hydrochloric acid propanolysis. J Chromatogr 445:285-289. doi:10.1016/ S0021-9673(01)84535-0

Rose MD, Winston F, Hieter P (1990) Methods in yeast genetics: a laboratory manual. Cold Spring Harbor Laboratory, Cold Spring Harbor

Shiraki M. Endo T, Saito T (2006) Fermentative production of (R)-(-)-3hydroxybutyrate using 3-hydroxybutyrate dehydrogenase null mutant of Ralstonia eutropha and recombinant Escherichia coli. J Biosci Bioeng 102:529-534. doi:10.1263/jbb.102.529

Sutter MA, Seebach D (1983) Synthesis of (2E, 4E, 6S, 7R, 10E, 12E,14S, 15R)-6, 7, 14, 15-tetramethyl-8, 16-dioxa-2, 4, 10, 12-cyclohexadecatetraene-1, 9-dione-a model system for elaiophylin. Liebigs Ann Chem 6:939-949. doi:10.1002/jlac.198319830607

Tanaka A, Ohnishi N, Fukui S (1967) Studies on the formation of vitamins and their function in hydrocarbon fermentation. Production of vitamin B6 by Candida albicans in hydrocarbon medium. J Ferment Technol 45:617-623

Tasaki O, Hiraide A, Shiozaki T, Yamamura H, Ninomiya N, Sugimoto H (1999) The dimer and trimer of 3-hydroxybutyrate oligomer as a precursor of ketone bodies for nutritional care. J Parenter Enter Nutr 23:321-325. doi:10.1177/0148607199023006321

Terentiev Y, Breuer U, Babel W, Kunze G (2004) Non-conventional yeasts as producers of polyhydroxyalkanoates-genetic engineering of Arxula adeninivorans. Appl Microbiol Biotechnol 64:376-381. doi:10.1007/ s00253-003-1498-x

Tseng HC, Martin CH, Nielsen DR, Jones Prater KL (2009) Metabolic engineering of Escherichia coli for enhanced production of (R)- and (S)3-hydroxybutyrate. Appl Environ Microbiol 75:3137-3145. doi:10.1128/ AEM.02667-08

Wartmann T, Böer E, Pico AH, Sieber H, Bartelsen O, Gellissen G, Kunze G (2003) High-level production and secretion of recombinant proteins by the dimorphic yeast Arxula adeninivorans. FEMS Yeast Res 2:363-369. doi:10.1111/j.1567-1364.2002.tb00105.x

Yun JE, Kwak S, Kim RS, Park YC, Jin YS, Kim KH (2015) Production of (S)-3-hydroxybutyrate by metabolically engineered Saccharomyces cerevisiae. J Biotechnol 209:22-30. doi:10.1016/j.jbiotec.2015.05.017

\section{Submit your manuscript to a SpringerOpen ${ }^{\odot}$ journal and benefit from:}

- Convenient online submission

- Rigorous peer review

- Immediate publication on acceptance

- Open access: articles freely available online

- High visibility within the field

- Retaining the copyright to your article

Submit your next manuscript at $\boldsymbol{\nabla}$ springeropen.com 